\title{
INVESTIGATION OF THE EFFECT OF A HYBRID DRYING METHOD ON THE COLOR QUALITY OF NECTARINE SLICES AND ENERGY CONSUMPTION
}

\author{
FATMAGÜL MUTLU DEMIREL ${ }^{a}$, OSMAN ISMAIL ${ }^{b, *}$
}

\begin{abstract}
The main objective of a product quality study for drying agricultural products without causing distortion is to reduce the product moisture value to a final moisture value while expending the least energy and time. In the first stage of this study, nectarine slices were dried in a microwave and cabinet dryer under different drying conditions. Experiments in the microwave dryer were done at four different power levels: 90, 180, 360, and $600 \mathrm{~W}$. Hot air drying was done at two temperatures, 50 and $70{ }^{\circ} \mathrm{C}$, with a constant air velocity $(2.0 \mathrm{~m} / \mathrm{s})$. In the second stage, after those experiments, the hybrid drying method were constructed based on the color parameter, and moisture ratio. In the hybrid drying method, hot air drying was carried out with microwave pretreatment. The most effective hybrid drying method in terms of optimal drying time, energy consumption, and color parameters was found to be at $180 \mathrm{~W}$ microwave power and $70^{\circ} \mathrm{C}$.
\end{abstract}

Keywords: Nectarine, hybrid drying, color, energy consumption

\section{INTRODUCTION}

Nectarine (Prunus persica var. nectar maxim) is a summer-borne fruit of the Rosaceae family. The nectarine is not a different species from the peach but rather a sub-variety of the peach with recessive genes, and because it lacks fuzz or short hairs it is sometimes referred to as a "shaved peach" or "fuzz-less peach" [1]. The Food and Agriculture Organization of the United

\footnotetext{
a T.R. Ministry of Culture and Tourism, Directorate of Central and Laboratory for Restoration and Conservation, İstanbul, Turkey

b Yildiz Technical University, Davutpasa Campus, Faculty of Chemical and Metallurgical Engineering, Department of Chemical Engineering, 34210 Esenler, Istanbul, Turkey

* Corresponding Author: ismail@yildiz.edu.tr
} 
Nations (FAOSTAT) statistical data showed that the yield of peaches and nectarines world-wide is about 21 million tons. Turkey produced 575,730 tons in 2012 [2].

The ripened nectarine is perishable and deteriorates rapidly after harvesting, hence the need to apply an appropriate postharvest technology to prolong the shelf life of the fruit; drying is among the most frequently used methods for that purpose [3-5]. Drying is a mass transfer process consisting of the removal of water or another solvent by evaporation from a solid, semisolid or liquid. Drying is one of the most commonly used processes to improve food stability, because it decreases the water activity of the material considerably, reduces microbiological activity, and minimizes physical and chemical changes during storage $[3,6]$.

Fruits and vegetables have a high initial moisture content and suffer alterations of their original form during the drying process through significant shrinkage. Hot air drying has many disadvantages such as lower energy efficiency and long drying times, but despite that it has been used widely $[7,8]$. Because of the low thermal conductivity of foods, heat transfer to the inner sections during conventional heating is limited. To reduce the processing time, hence to accelerate the drying process, some obstacles must be overcome. Fast and effective thermal processing has resulted in the increasing use of microwaves for food drying. This technique has been extensively employed both in the food and the chemical engineering industries [9]. The internal temperature reached by food dried by microwave drying is higher than the surface temperature, and a more dynamic moisture transfer is accomplished compared with that by convection drying [10]. Because of its quick drying ability, high energy efficiency, and fewer drying area concerns, microwave drying is an acceptable alternative method to convection drying [11]. Microwave drying of biological products, such as fruits and vegetables with high moisture content, is very advantageous $[12,13]$. Several studies have been carried out to compare the advantages of microwave and convection drying of agricultural materials, for example, for okra [14], mango ginger [15], grape [16], and garlic [17].

Drying causes changes in food properties including discoloration, aroma loss, nutritive value, and changes in physical appearance and shape. A higher drying temperature reduces the drying time but may result in poor product quality, heat damage to the surface, and higher energy consumption. In contrast, drying conditions at a lower temperature may improve the product quality but decrease the drying rate thus lengthening the drying time [18]. Therefore, any small improvement in energy efficiency in the food drying process will lead to a sustainable development from the global energy perspective [19]. 
Hybrid drying combines the advantages of microwave and hot air. The hybrid process can be operated at low temperatures with high energy efficiency and with better retention of the original color of food and heatsensitive nutrients. Although some investigations have focused on the drying characteristic of peaches, there is no information on the drying of nectarines a sub variety of the peach. The purpose of the present work is to investigate the effect of microwave, hot air, and hybrid (microwave pretreatment plus hot-air) drying methods on the drying time, color quality of nectarine slices, and the concomitant energy demand. Another objective of studying the hybrid drying method is to investigate its differences by comparison with other drying methods.

\section{RESULT AND DISCUSSION}

\section{Drying Curves}

The drying curves (time versus moisture content) of the nectarine slices dried at different microwave power levels are presented in Figure 1.

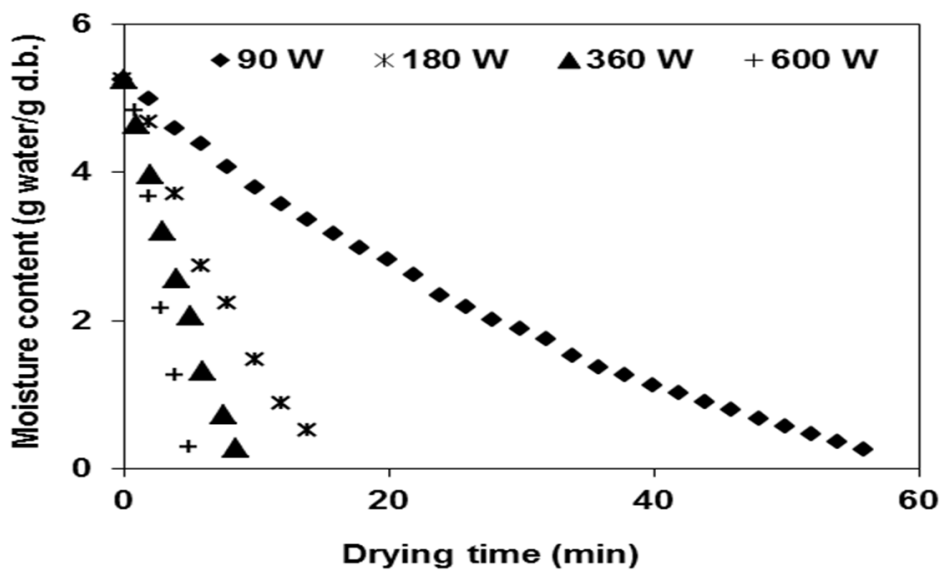

Figure1. Drying curves of nectarine slices at different microwave power levels

The moisture content of nectarine slice samples was calculated by a simplified version of Eq. (1).

$$
M_{\text {initial }}=\frac{W_{w}-W_{d}}{W_{d}}
$$


Drying curves were used to determine the effect of microwave power levels on the drying time: microwave power level is a very important factor in the drying procedure. Water molecules at increased microwave output power with a given frequency are subjected to a greater number of electromagnetic waves. Thus, more heat is produced in the nectarine slices, thus accelerating evaporation of water molecules. The moisture ratio decreased exponentially with time in nectarine slice samples, in agreement with the results reported under different conditions in which peach samples were dried [10, 20]. In the microwave, final moisture content was attained at about 56 min of $90 \mathrm{~W}$ output power, and this value was calculated as approximately 15,8 , and 5 min for 180,360 , and $600 \mathrm{~W}$ output power, respectively.

The characteristic drying curves showing the changes in moisture ratio of the nectarine slices with time at drying temperatures of 50 and $70{ }^{\circ} \mathrm{C}$ are given in Figure 2.

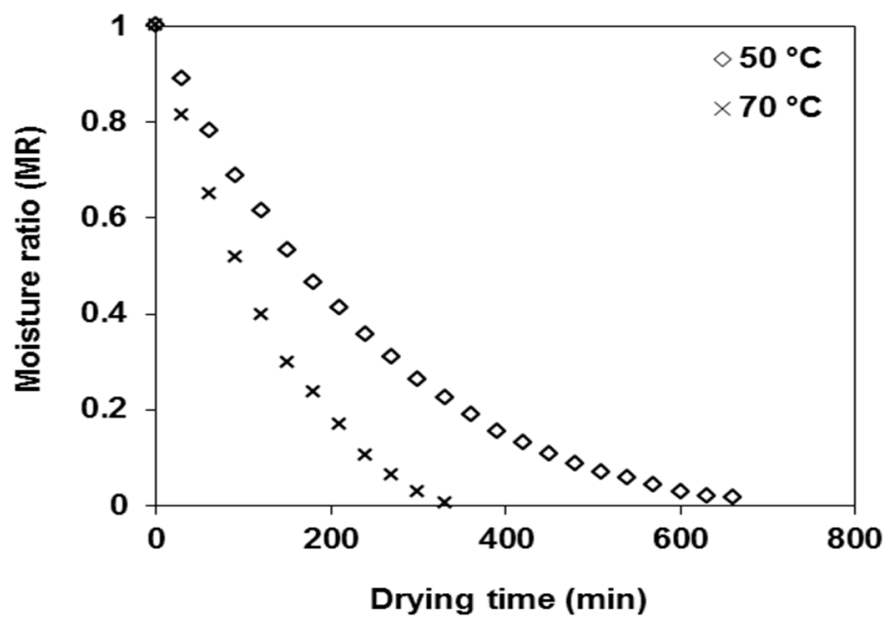

Figure 2. Experimental moisture ratio of nectarine slices versus drying time

The moisture ratio of nectarine slice samples was calculated using a simplified version of Eq. (2).

$$
M R=\frac{M_{t}-M_{e}}{M_{o}-M_{e}}
$$

It is clear that the drying air temperature had a significant effect on the drying time. As shown in Figure 2, the higher air temperature of $70{ }^{\circ} \mathrm{C}$ results in a higher drying rate compared with that at $50^{\circ} \mathrm{C}$, as expected. Therefore, at higher temperatures mass transfer is more rapid and water loss is more 
excessive. Decreasing drying time with an increase in the drying air temperature has been reported for many agricultural products such as orange slices [21] and okra slices [22]. It is apparent that moisture ratio decreases continuously with drying time. From Figure 2, it is observed that the drying time required for reducing the moisture content of nectarine slices was 660 and $330 \mathrm{~min}$, at the air temperatures of 50 and $70{ }^{\circ} \mathrm{C}$, respectively. The drying air temperature of $70{ }^{\circ} \mathrm{C}$ resulted in a shorter drying time than that in $50{ }^{\circ} \mathrm{C}$ by approximately $330 \mathrm{~min}$ for nectarine slice samples.

\section{The selection of hybrid drying method}

Hybrid drying is applied combining hot air drying with a microwave pretreatment. The samples were initially dried by microwave for 2-30 min until the water content dropped to $65 \%-70 \%$ of the initial value, and then hot-air dried to the final water content. An orthogonal design was used to produce the optimal parameters. The synthetic evaluation index values are given in Table 1.

Table 1. Synthetic evaluation index (SEI) for each drying microwave power levels and hot-air temperatures

\begin{tabular}{cccc}
\hline Microwave $(\mathbf{W})$ & $\mathbf{T}\left({ }^{\circ} \mathbf{C}\right)$ & $\mathbf{t}(\mathbf{m i n})$ & Synthetic evaluation index (SEI) \\
\hline 90 & 50 & 335 & $0.74 \pm 0.03$ \\
90 & 70 & 205 & $0.78 \pm 0.07$ \\
180 & 50 & 282 & $0.78 \pm 0.08$ \\
180 & 70 & 160 & $0.80 \pm 0.05$ \\
360 & 50 & 276 & $0.48 \pm 0.10$ \\
360 & 70 & 154 & $0.59 \pm 0.08$ \\
600 & 50 & 272 & $0.41 \pm 0.13$ \\
600 & 70 & 151 & $0.36 \pm 0.11$ \\
\hline
\end{tabular}

The drying method that yielded the highest synthetic evaluation index value was the lowest level of combination drying, i.e. $\mathrm{MW}=180 \mathrm{~W}, \mathrm{~T}=70{ }^{\circ} \mathrm{C}$; therefore, hybrid drying at this level produces an acceptable final product in terms of color, moisture content and moisture ratio, with relatively rapid dehydration properties and within a relatively short processing time.

\section{Selected hybrid drying}

Two different combination levels were applied in combination drying: using a microwave power level of $180 \mathrm{~W}$ and air temperatures of 50 and $70{ }^{\circ} \mathrm{C}$. The moisture-time graphic obtained by fixing the temperatures at 50 and $70{ }^{\circ} \mathrm{C}$ 
and combining them with microwave power level of $180 \mathrm{~W}$ is shown in Figure 3. The drying process is characterized by a progressive decreasing in the moisture content with time.

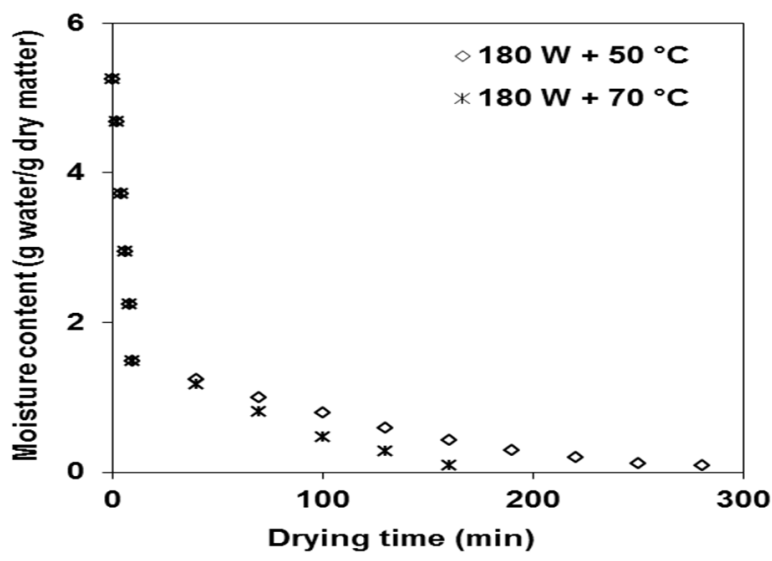

Figure 3. Variation of moisture content with drying time

In both hybrid drying methods, $70 \%$ of the total moisture content of the samples was removed by microwave drying. The remaining moisture was dried up to $0.085 \pm 0.01$ (g water/g dry matter) as final moisture content via hot air at 50 and $70{ }^{\circ} \mathrm{C}$. In the microwave and hot air combined drying process, the drying time was determined to be $10 \mathrm{~min}$ at $180 \mathrm{~W}$ power and 270 and 150 minutes for temperatures at 50 and $70{ }^{\circ} \mathrm{C}$, respectively. As seen in Figure 3, the drying period was shortened by increasing the drying temperature at a constant microwave power level. The decrease in the drying period can be attributed to increased internal vapor pressure at the high power level and high temperature. Combined drying processes at $70^{\circ} \mathrm{C}$ were completed within the shortest time in each of the constant power levels, whereas those at $50{ }^{\circ} \mathrm{C}$ needed the longest time for completion. Accordingly, the shortest drying time in combination trials was obtained through the drying process consisting of the combination of $180 \mathrm{~W}$ microwave power and $70^{\circ} \mathrm{C}$ temperature for $160 \mathrm{~min}$, whereas the longest drying process resulted from the combination of $180 \mathrm{~W}$ and $50{ }^{\circ} \mathrm{C}$ in which the temperature was kept at a minimum for $280 \mathrm{~min}$. As expected, a strong effect of microwave power level and temperature on moisture content was observed, as reported in the literature [16, 23, 24].

\section{Color Analysis}

The samples surface color was measured with a Minolta Chroma Meter CR-400 (Konica Minolta Sensing Inc., Japan) at three different edge spots on the surface of each sample before and after the drying treatment. The mean 
values of the measured data are described as the color values in this study. The color values were expressed as " $L$ " (whiteness/darkness), "a" redness/greenness), and "b" (yellowness/blueness).

The color difference $(\Delta E)$ was determined using the following Equation 3 [25]. $L_{0}, a_{0}$ and $b_{0}$ are the parameter values before drying the fresh nectarine samples.

$$
\Delta E=\sqrt{\left.\left(L_{o}-L\right)^{2}+\left(a_{0}-a\right)^{2}+\left(b_{0}-b\right)^{2}\right)}
$$

The fresh nectarine slices had values $62.19,10.31$, and 19.72 for " $L$ ", "a", and " $b$ ", respectively. Table 2 show the color data in terms of Hunter " $L$ ", "a" and " $b$ " values of dried nectarine slices obtained by different drying methods under different conditions. Also, before and after the drying process, $\Delta E$ and $(a / b)$ values of nectarine slices were calculated; these results are given in the Table 2.

Table 2. Color parameter values of dried nectarine slices

\begin{tabular}{|c|c|c|c|c|c|c|}
\hline \multirow{2}{*}{$\begin{array}{l}\text { Drying } \\
\text { methods }\end{array}$} & \multirow{2}{*}{$\begin{array}{c}\text { Drying } \\
\text { conditions }\end{array}$} & \multicolumn{3}{|c|}{ Color Parameters } & \multirow{2}{*}{$\Delta E$} & \multirow{2}{*}{$(a / b)$} \\
\hline & & $L$ & $a$ & $b$ & & \\
\hline \multirow[t]{4}{*}{ Microwave } & $90 \mathrm{~W}$ & 53.85 & 11.10 & 19.47 & 8.38 & 0.57 \\
\hline & $180 \mathrm{~W}$ & 52.92 & 12.89 & 20.91 & 9.69 & 0.61 \\
\hline & $360 \mathrm{~W}$ & 49.85 & 13.57 & 19.69 & 12.76 & 0.70 \\
\hline & $600 \mathrm{~W}$ & 40.68 & 11.90 & 9.97 & 23.66 & 1.19 \\
\hline \multirow[t]{2}{*}{ Hot-air } & $50^{\circ} \mathrm{C}$ & 71.33 & 16.27 & 33.58 & 17.64 & 0.36 \\
\hline & $70^{\circ} \mathrm{C}$ & 74.56 & 10.32 & 36.80 & 21.08 & 0.28 \\
\hline \multirow[t]{6}{*}{ Hybrid } & $90 \mathrm{~W}+50^{\circ} \mathrm{C}$ & 65.61 & 15.03 & 31.99 & 13.58 & 0.46 \\
\hline & $90 \mathrm{~W}+70{ }^{\circ} \mathrm{C}$ & 69.85 & 14.22 & 34.35 & 16.97 & 0.41 \\
\hline & $180 W+50^{\circ} \mathrm{C}$ & 69.91 & 11.39 & 30.64 & 13.41 & 0.35 \\
\hline & $180 \mathrm{~W}+70^{\circ} \mathrm{C}$ & 73.01 & 11.19 & 34.33 & 18.20 & 0.32 \\
\hline & $360 \mathrm{~W}+50^{\circ} \mathrm{C}$ & 54.15 & 15.14 & 28.43 & 12.79 & 0.53 \\
\hline & $360 \mathrm{~W}+70^{\circ} \mathrm{C}$ & 56.03 & 14.67 & 28.23 & 11.34 & 0.52 \\
\hline
\end{tabular}

The temperature and drying time are the main factors affecting the color change of material during drying process [26]. Table 2 shows that " $L$ ", "a" and " $b$ " values increased as the drying air temperature increased from $50^{\circ} \mathrm{C}$ to $70{ }^{\circ} \mathrm{C}$. To the contrary, the lightness values $(8.34,9.27,12.34$, and 21.51 at $90,180,360$, and $600 \mathrm{~W}$, respectively) decreased as microwave power level increased, and slice colors darkened. In some cases, blackness occurred. The amounts of sugar, acids ( $\mathrm{pH}$ ), and amino acids, as well as time of processing, have been reported to affect the color of processed products by causing 
formation of brown pigments [27]. After hybrid drying of the nectarine slices, an increase in the lightness (an "a" increase in the " $L$ " value) was observed (Table 2): "a" and " $b$ " increased in all the dried samples when compared with fresh nectarine slices. Visually, the redness and yellowness increased. The total color difference $(\Delta E)$, as calculated by Equation (3), allows a simple way of identifying the possible changes occurring when comparing one set of coordinates with the reference set, which in the present case was the fresh state. Table 2 shows the values of color difference for the nectarine slices under various drying conditions. The lowest changes occurred at the lowest temperature and microwave power level. The color difference parameter had a value of 17.64 for the nectarine slices dried at the lower temperature $\left(50{ }^{\circ} \mathrm{C}\right)$ and increased to 21.08 at the highest temperature $\left(70^{\circ} \mathrm{C}\right)$. The color difference value of the nectarine slices samples dried with the hybrid method at $(180 \mathrm{~W}+$ $\left.50{ }^{\circ} \mathrm{C}\right)$ and $\left(180 \mathrm{~W}+70^{\circ} \mathrm{C}\right)$ was 13.41 and 18.20 , respectively. The higher " $L$ " and lower "a/b" values are preferred in dried food products [28]. From these results, drying at $70^{\circ} \mathrm{C}$ was found to be the optimal temperature for nectarine slices. Also, hot air drying with microwave pretreatment had an important effect on the color of nectarine slices.

\section{Energy Consumption}

The energy consumption values obtained in the drying trials carried out using the three different drying methods are given in the Figure 4.
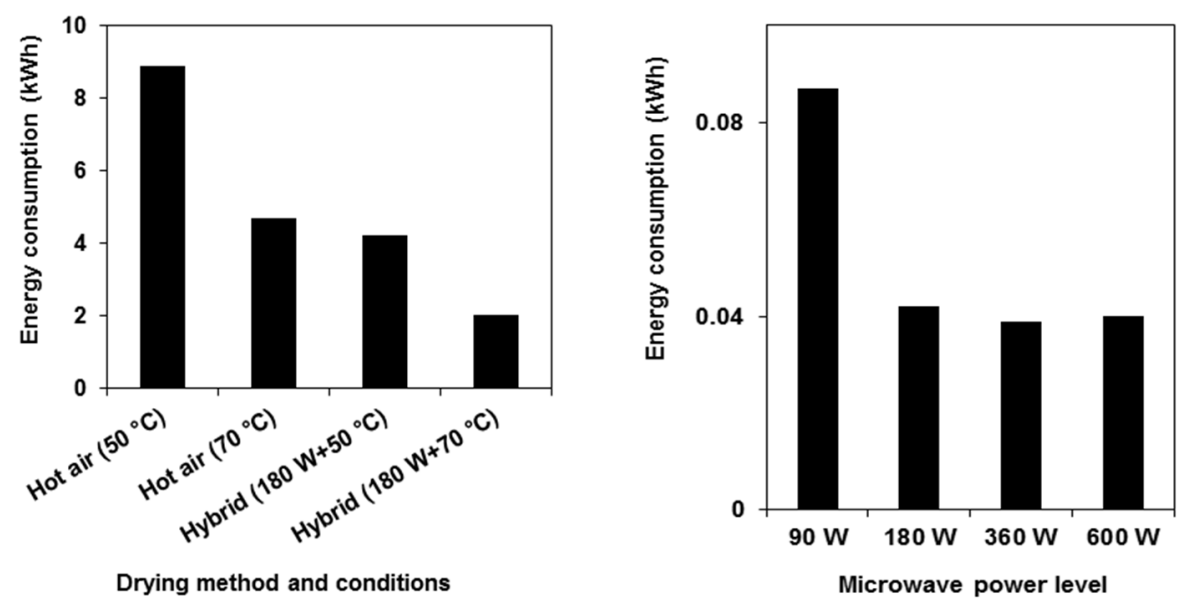

Figure 4. Energy consumption versus different drying methods of nectarine slices during the drying process 
When three different drying methods were compared with the associated energy consumption values, the lowest energy consumption occurred in the microwave drying method, followed by the hybrid and the hot air drying methods. The energy consumption decreases with the increasing air temperature and power level. Among all the drying methods, the optimal energy consumption was obtained through microwave drying at $180 \mathrm{~W}$ power: energy consumption at this level was $0.042 \mathrm{kWh}$. Among all the drying methods the highest value of energy consumption was obtained in the hot-air drying process at $50{ }^{\circ} \mathrm{C}$ and $8.91 \mathrm{kWh}$. Energy consumption was 0.039-0.087, 2.03-4.25, and 4.72-8.91 $\mathrm{kWh}$ for microwave, hybrid, and hot air drying, respectively.

\section{CONCLUSIONS}

In this study, nectarine slices were dried by three different methods, and the following conclusions were reached. First, nectarine slices dried in a microwave dryer at 90,180, 360, and $600 \mathrm{~W}$ microwave power levels could not obtain the desired color parameters. In microwave drying, the color quality decreases as the microwave power level increases. Second, for nectarine slices dried in a cabin dryer at 50 and $70{ }^{\circ} \mathrm{C}$ with hot air was effective for the desired color values. The color quality increases as the air temperature increases. Finally, to obtain the positive effects of these two drying methods, the color quality was used as a basis for a hybrid drying method. A combination of microwave and convective drying at microwave power of $180 \mathrm{~W}$ and air temperature of $70{ }^{\circ} \mathrm{C}$ resulted in a dehydrated product with optimal quality within the range of experimental conditions studied. The hybrid drying method yielded good results in terms of drying time, energy consumption, and color.

\section{EXPERIMENTAL SECTION}

\section{Materials}

Fresh nectarines (Prunus persica var. nectarina maxim) were purchased from a local market in İstanbul, Turkey and kept at $4{ }^{\circ} \mathrm{C}$ prior to experiments. The initial moisture content of the fresh nectarines was determined using the Association of Official Analytical Chemists method [29]. The average initial moisture content of the nectarines was $84 \%$ (w.b.).

\section{Drying Procedures}

Before each drying process, the nectarine samples were washed and cut into $1 \pm 0.2 \mathrm{~cm}$ thick slices. 
The microwave drying experiments were carried out in a Robert Bosch Hausgerate $\mathrm{GmbH}$ (Germany) model microwave oven, which has a maximum output of $800 \mathrm{~W}$ working at $2450 \mathrm{MHz}$. The adjustment of microwave output power and processing time was done with the digital control facility located on the microwave oven. Drying experiments was carried out using sliced nectarines with a weight of about of $30 \pm 2 \mathrm{~g}$ arranged as thin layer on the rotatable plate fitted inside the microwave oven cabin. The rotating plate provides for equal distribution of microwave radiation energy throughout the sample. Drying was performed at a single power level. In the microwave drying method, four power levels of $90,180,360$, and 600 Watts were used. Moisture loss was measured during $60 \mathrm{~s}$ intervals with a digital balance (Precisa, model XB220A, Precisa Instruments AG, Dietikon, Switzerland) with an accuracy of $0.001 \mathrm{~g}$. Microwave drying continued until the moisture was reduced to about $0.18 \mathrm{~g}$ water/g (on a dry basis) of the initial moisture content.

Drying experiments were performed in a cabinet-type dryer (API \& PASILAC Limited of Carlisle, Cambria, UK). In each experiment, $100 \pm 2 \mathrm{~g}$ of nectarine slices was used. Drying experiments of nectarine slices were conducted at two temperatures, 50 and $70^{\circ} \mathrm{C}$, at a constant air velocity $(2.0 \mathrm{~m} / \mathrm{s})$. Moisture loss in the nectarine slices was measured with a balance and recorded at $30 \mathrm{~min}$ intervals. Drying was considered complete when the moisture content of the samples was approximately $0.085 \mathrm{~g}$ water $/ \mathrm{g}$ dry matter (dry basis) at air temperatures of 50 and $70{ }^{\circ} \mathrm{C}$, respectively.

Drying conditions were determined after pre-experiments; $30 \mathrm{~g}$ of nectarine slice samples was used for drying. Eight levels of combined drying (comprising the two convective and four microwave settings described previously) were investigated $\left(50\right.$ and $\left.70^{\circ} \mathrm{C}\right) \times(90,180,360$, and $600 \mathrm{~W})$. Drying was considered complete when the moisture content of the samples was approximately $0.085 \pm 0.01 \mathrm{~g}$ water $/ \mathrm{g}$ dry matter (dry basis).

\section{Synthetic evaluation index}

The synthetic evaluation index (SEI) was used in the hybrid drying method and adopted to reflect the contributions of moisture ratio and dried product quality. The quality parameters measured in the study were ranked in order of significance as follows: color, moisture content, moisture ratio, and assigned weights $\left(\lambda_{1}, \lambda_{2}, \lambda_{3}\right)$ of $0.3,0.2,0.1$, respectively. The SEI [25] was then calculated for each of the experimental conditions by the following Equation 4.

$$
\begin{gathered}
S E I=\sum_{i=1}^{3} \lambda_{i} Y_{i} \\
Y_{1}=1-\frac{\Delta E-\Delta E_{\min }}{\Delta E_{\max }-\Delta E_{\min }} ; Y_{2}=\frac{X_{d}-X_{o}}{T_{A D}+T_{M W D}} ; Y_{3}=\frac{M R-M R_{\min }}{M R R_{\max }-M R_{\min }}
\end{gathered}
$$


where $M R$ is the moisture ratio, $X_{d}$ and $X_{0}$ are the water contents of the dehydrated sample and the fresh sample on dry basis. $T_{A D}$ and $T_{M W D}$ are the drying times of air drying process and microwave drying process, respectively.

\section{Energy Consumption}

The energy consumption value required for drying nectarine slices in the microwave was calculated with Equation 5 [30].

$$
E_{t}=P^{*} t
$$

where $E_{t}$ is the energy consumption $(\mathrm{kWh}), P$ is the microwave output power $(\mathrm{kW}), t$ is the drying time (h).

In hot air drying, the drying process energy consumption was measured for the drying and blowing air by electric heater and fan. The energy consumption value was calculated with Equation 6 [31]:

$$
E_{t}=\rho_{a} \cdot A \cdot v \cdot c_{p} \cdot \Delta T \cdot D_{t}
$$

where $\rho_{a}$ is the air density $\left(\mathrm{kg} / \mathrm{m}^{3}\right), A$ is the tray area $\left(\mathrm{m}^{2}\right), u$ is the air velocity $(\mathrm{m} / \mathrm{sec}), c_{p}$ is the specific heat $\left(\mathrm{kJ} / \mathrm{kg}{ }^{\circ} \mathrm{C}\right), \Delta T$ is a temperature difference between the air inlet and outlet of the dryer $\left({ }^{\circ} \mathrm{C}\right)$, and $D_{t}$ is the total drying time of each sample $(h)$.

\section{REFERENCES}

1. M. Rieger, Peach: http//www.uga.edu.fruit/peach.html 2007.

2. FAO, FaoStat: Agriculture data, http://faostat3.fao.org/download/Q/QC/E. Accessed November 23, 2014.

3. M.K. Krokida, D. Marinos-Kouris, Journal of Food Engineering, 2003, 57, 1.

4. M. A. Karim, M. N. A. Hawlader, International Journal of Heat and Mass Transfer, 2005, 48, 4914.

5. B. Alaei, R. Amiri Chayjan, Acta Scientiarum Polonorum, 2015, 14, 15.

6. A. Midilli, H. Kucuk, Z. Yapar, Drying Technology, 2002, 20, 1503.

7. H. Feng, J. Tang, R.P. Cavalieri, Transactions of the ASAE, 2002, 45, 129.

8. Z. Pan, R. Khir, L.D. Godfrey, R. Lewis, J.R. Thompson, A. Salim, Journal of Food Engineering, 2008, 84, 469.

9. J. Bondaruk, M. Markowski, W. Blaszczak, Journal of Food Engineering, 2007, $81,306$.

10. J. Wang, K. Sheng, LWT-Food Science and Technology, 2006, 39, 247.

11. A. Harish, M. Rashmi, T.P. Krishna Murthy, B.M. Blessy, S. Ananda, International Food Research Journal, 2014, 21, 1081.

12. A.K. Datta, S.S.R. Geedipalli, M.F. Almeida, Food Technology, 2005, 59, 36. 
13. D. Arslan, M.M. Özcan, LWT- Food Science and Technology, 2010, 43, 1121.

14. L.V. Mana, T. Orikasab, Y. Muramatsuc, A. Tagawaa, Journal of Food Processing \& Technology 2012, 3, 1.

15. T.P. Krishna Murthy, B. Manohar, International Journal of Food Science \& Technology, 2012, 47, 1229.

16. I. Alibas, International Journal of Food Science \& Technology, 2014, 10, 69.

17. A. Calín-Sánchez, A. Figiel, A. Wojdylo, M. Szaryez, A.A. Carbonell-Barrachina, Food and Bioprocess Technology, 2014, 7, 398.

18. C. Kumar, M.A. Karim, U.H.J. Mohammad, Journal of Food Engineering, 2014, $121,48$.

19. T. Kudra, Drying Technology, 2004, 22, 917.

20. A. Zhu, X. Shen, International Journal of Heat and Mass Transfer, 2014, 72, 345.

21. S. Rafiee, M. Sharifi, A. Keyhani, M. Omid, A. Jafari, S.S. Mohtasebi, H. Mobli, International Journal of Food Properties, 2010, 13, 32.

22. P.K. Wankhade, R.S. Sapkal, V.S. Sapkal, Procedia Engineering, 2013, 51, 371.

23. O. Eştürk, Y. Soysal, Journal of Agricultural Science, 2010, 16, 26.

24. S. Minaei, A. Motevali, G. Najafi, S.R. Mousavi Seyedi, Australian Journal of Crop Science, 2011, 6, 584.

25. A. Jiao, X. Xu, Z. Jin, Food and Bioproducts Processing, 2014, 92, 259.

26. P. Somkiat, P. Paveena, S. Somchart, Drying Technology, 2004, 22, 2095.

27. W.A. Gould, The AVI Publishing Company, Inc., Westport, CT, USA, 1983, chapter 8.

28. O. İsmail, A.K. Figen, S. Pişkin, Heat Mass Transfer, 2015, 51, 807.

29. AOAC, Official Methods of Analysis of AOAC International, 16th edn., AOAC International, Virginia, 1995.

30. A. Motevali, S. Minaei, M.H. Khoshtagaza, Energy Conversion and Management, 2011, 52, 1192.

31. M. Aghbashlo, M.H. Kianmehr, H. Samimi-Akhijahani, Energy Conversion and Management, 2008, 49, 2865. 